\title{
Global Luck Egalitarianism and Border Control
}

Kim Angell and Robert Huseby ${ }^{1}$

\begin{abstract}
This paper discusses what implications Global Luck Egalitarianism (GLE) has for border control. Some authors suggest that an open borders policy follows from GLE. The idea is that various unchosen inequalities inevitably follow from differences in birthplace, such that GLE will always have principled reason to condemn closed borders. Others are skeptical to the assumption that GLE will have liberal implications for border control, because open borders may have other, adverse, effects that outweigh the reductions in unjust inequality. Against such skeptics, we argue that GLE will (typically) have quite liberal implications for border control. However, this connection is not a principled one: whether (and to what extent) GLE favors opening or closing borders will depend upon empirical circumstances.
\end{abstract}

Key Words: Border control - Brain drain - Global Luck Egalitarianism - Immigration

\footnotetext{
${ }^{1}$ Earlier versions of this paper was presented at seminars and workshops at the University of Gothenburg, the University of Oslo, and Oslo and Akershus University College of Applied Sciences. We are grateful to Chris Armstrong, Sarah Fine, Jakob Elster, Edmund Henden, Fredrik Dybfest Hjorthen, Nils Holtug, Patti Lenard, Anders Molander, Cara Nine, Kieran Oberman, Göran Duus-Otterström, and two anonymous reviewers for many helpful comments.
} 


\section{Introduction}

In debates about distributive justice, luck egalitarianism has received substantial attention in recent years. As far as global distributive justice is concerned, however, the theory has been less dominant (though not absent). ${ }^{2}$ In this paper we discuss what implications global luck egalitarianism (GLE) may have for the important question of whether states are justified in (completely or partially) closing their borders to outsiders seeking entrance. ${ }^{3}$ As should be evident, the answer will depend to some extent on the actual state of the world, but we think that there are nevertheless some theoretical points worth making about the issue.

We start, in the next section, by briefly presenting luck egalitarianism and GLE. While our aim is not to justify GLE as such, ${ }^{4}$ we nevertheless point to some intuitive support for the general ideal. Further, in section 3, we discuss some methodological questions. Subsequently, in section 4, we offer some initial reason to think that GLE is relevant for the question of the extent to which states can justifiably close their borders, and more specifically, some reasons to think that GLE's implications would be rather liberal in this regard. ${ }^{5}$ We then consider some

\footnotetext{
${ }^{2}$ Note that some authors distinguish between global justice, and international justice, where the former refers to relations between individuals, and the latter to relations between states (Brock 2015, Caney 2005: 2). We will mostly be concerned with individuals.

${ }^{3}$ For recent important discussions relevant to the theme of this paper, see Carens (2013), and Miller (2016). Holtug (2017) discusses the related question of whether GLE can justify asymmetrical rights between immigrants and citizens.

${ }^{4}$ In part because we do not agree on whether it is, in the end, defensible. We do think, though, that GLE is interesting and plausible enough to merit serious consideration.

${ }^{5}$ We do not address objections to luck egalitarianism as such. We assume that luck egalitarianism is plausible in order to, first, spell out a version of it in the global context, and then, more centrally, ask what implications the
} 
arguments that indicate an opposite conclusion (section 5). We argue that GLE will, for the most part, have liberal implications for border control, but that there may be exceptions, for instance in cases where open borders will result in the worst off in sender countries becoming unjustly worse off in absolute terms; in cases where open borders threatens to produce more unjust inequality in receiver countries; and in cases where unchecked immigration lead to economic costs in receiver countries, with associated (prohibitive) welfare losses. Empirically, these possibilities are to some extent contested. We take no stand in those debates, but hold that GLE will have liberal implications up to the point at which such adverse effects become sufficiently large. Section 6 concludes.

Before proceeding, two clarifications are in order. First, when we refer to immigrants (and immigration), we intend to refer to people who wish to move from one state in order to settle in another, (see Wellman and Cole 2011, 1), but who are not victims of persecution (and hence do not legally qualify as refugees, according to the UN Convention). ${ }^{6}$ It seems safe to say that the category of immigrants we focus on will be quite sizeable. It is also worth noting that, persecuted and severely deprived people aside, very many (but of course not all) immigrants will still be badly off and needy in a more general sense of the term.

Secondly, by the term 'closed borders' we do not mean to imply that states tend to, or are permitted to, close their borders completely. We assume that states honor international conventions, and that they have a duty to admit (some number of) Convention-refugees, people

\footnotetext{
global version will have for the question of border control. For criticisms of luck egalitarianism in general, see for instance Anderson (1999); Eyal (2006); Scheffler (2003).

${ }^{6}$ There is debate about the most plausible definition of refugees. We do not engage in that debate here. See Lister (2013); Miller (2016, ch. 5); Schacknove (1995). Note, however, that on the so-called 'humanitarian' definition (Shacknove 1995), people in severe need might be classified as 'refugees' regardless of whether they are also persecuted.
} 
with other special claims to entrance (arising from, for instance, family reunification), and possibly people who are otherwise in severe need. The general question is thus whether states have a right to deny entry to people who want to enter and settle (temporarily or permanently), but who do not fall into any of the said categories. We also assume that when a state opens its borders for a person, this typically gives access, at least over time, to various other benefits that contribute to people's welfare (such as economic, social and political rights).

\section{Luck Egalitarianism, Global Luck Egalitarianism, and Border Control}

Luck egalitarianism (LE) encompasses a relatively large family of ideas, and we cannot here offer an exhaustive categorization. ${ }^{7}$ Many writers, however, agree that the intuitive core of luck egalitarianism is summed up in Temkin's oft-cited phrase: “...it is bad - unjust and unfair - for some to be worse off than others through no fault [or choice] of their own $(1993,13) . "{ }^{\prime 8}$ The main idea is that individuals should have equally much of whatever it is that we should distribute justly, unless they are themselves responsible for having less or more (than equally much). Luck egalitarianism thus incorporates two very appealing ideals, namely equality and personal responsibility (for one's level of advantage). Ordinarily, and quite reasonably, luck egalitarians also incorporate a concern for utility into their view. The upshot (as we will return to below) is that total utility gains sometimes must be weighed against gains in just equality.

While luck egalitarianism has been thoroughly discussed in the literature on distributive justice (in general), most theorists who write explicitly about global justice, even broadly egalitarian or cosmopolitan ones, endorse other (though often related) ideals, such as

\footnotetext{
${ }^{7}$ For more extensive treatments, see Arneson (2011); Knight (2009); Lippert-Rasmussen (2016).

${ }^{8}$ For similar formulations, see for instance Cohen (2011: 119), and Arneson (1989: 85).
} 
sufficientarianism, ${ }^{9}$ (forms of) libertarianism, ${ }^{10}$ utilitarianism, ${ }^{11}$ resource egalitarianism, ${ }^{12}$ or versions of Rawlsian egalitarianism. ${ }^{13,14}$ Caney’s cosmopolitanism, however, consists of several principles that combined come close to, but does not equal, luck egalitarianism, despite being clearly motivated by the unfairness of arbitrary (that is, unchosen) differences between people $(2005,122)$. Tan $(2012)$ is one of the few who explicitly advocate a global form of luck egalitarianism. He is, however, an institutionalist LE-advocate, according to which the workings of institutions need to be just, but not individual choices (cfr. Rawls 1999b). Most versions of luck egalitarianism, it seems, pertain to individual choices, and are thus noninstitutionalist (see Arneson 2011).

The idea of (non-institutionalist) global luck egalitarianism though, seems quite natural (Arneson, 2011, 42-46), and it could be the case that many luck egalitarians implicitly assume that their theories have a global scope. Recall the core idea that it is unfair for some to be worse off than others through no fault or choice of their own. As noted, the intuitive drives behind the view are commitments to equality and responsibility. You should not be worse off than others unless it is your own fault, and that which is not your fault is (as far as you are concerned) brute

\footnotetext{
${ }^{9}$ Miller 2007.

${ }^{10}$ Pogge 2005, Butt 2009. Note that it is only in the relation between states that Pogge and Butt can be described as libertarians.

${ }^{11}$ Singer 1971.

${ }^{12}$ Steiner 1981, 1994.

${ }^{13}$ Beitz 1979, Pogge 1994.

${ }^{14}$ Notable non-cosmopolitans include: Rawls 1999a, Nagel 2005, and Blake 2001.
} 
luck. ${ }^{15}$ Differential brute luck is unfair because it is outside our control. ${ }^{16}$ Reflecting upon these commitments, it seems likely that many advocates of LE, despite not always spelling it out, do not intend to restrict their theory to the view that it is unjust if and only if someone is worse off than a compatriot through no fault or choice of his own. ${ }^{17}$ It seems that most luck egalitarian views are compatible with, or even implies, GLE (though nothing in the present paper hinges on this).

A few writers are quite explicit, however. Arneson's luck prioritarian view (1999), when combined with his defense of extreme cosmopolitanism (2016) comes very close to GLE as understood here (at least if we agree with Arneson that prioritarianism [and sufficientarianism] are broadly egalitarian views). Finally, Fabre (2005) and Lippert-Rasmussen (2016, 165-173) are two theorists who clearly defend versions of GLE. ${ }^{18}$

There is, of course, a huge debate about what exactly it is that ought to be distributed equally. Here we simply assume that some version of (responsibility-adjusted) welfare is the most plausible equalisandum. We do not defend any particular theory of welfare, but accept the general idea that justice is primarily concerned with how well people's lives go, and not with, say, how many resources they have at their disposal. (Although we shall not attempt to show

\footnotetext{
${ }^{15}$ Dworkin (2000, 73). The parenthesized phrase allows for the possibility that others' freely chosen acts may become your brute luck.

${ }^{16}$ Luck egalitarianism is most often seen as compatible with differential option luck however. Option luck encompasses the outcomes of risks that are freely chosen (Dworkin $(2000,73)$.

${ }^{17}$ See Holtug (2017: 131). Note however, that Nagel (2005), drawing on Rawls (1999b) argues that morally arbitrary inequalities are problematic only within coercive political structures (though Rawls, arguably, does not defend luck egalitarianism, domestically or internationally [Scheffler 2003]). See also Tan (2012). Knight (2009, 5) also assumes that luck egalitarian justice applies primarily domestically, though it is not entirely clear why.

${ }^{18}$ See also Holtug (2017).
} 
this here, we expect that our arguments will be relevant also for [responsibility-adjusted] resourcist versions of global luck egalitarianism. $)^{19}$

Note also that we intend by luck egalitarianism, domestically or globally, something else than equality of opportunity (for welfare). The latter too comes in many versions, but the main point in the present context is that we assume that it is (responsibility-adjusted) welfare that should be distributed equally and not opportunities for welfare, or simply opportunities as such (see Miller 2007, 2016). The reason we want to avoid this, is that most versions of equality of opportunity for welfare (or advantage more generally) deem some cases of differential brute luck as just. ${ }^{20}$ As Lippert-Rasmussen (1999) has shown, this runs counter to the core claim of LE (which is not to indicate that equality of opportunity is for that reason implausible). Surely, ordinary LE can also be seen as distributing opportunities to some extent. But the term equality of opportunity often refer to starting gate-theories along the lines of Arneson (1989), and Vallentyne (2002). On these views, opportunities can be equal if, at some relevant point, agents are equally exposed to brute luck, even if they end up with differential (actual) brute luck. It is this latter implication we wish to avoid here.

To roughly sum up this section so far, let us briefly sketch what GLE would entail. Since we are assuming a global, non-institutionalist, individualist view of the theory, presumably it is unjust if someone is worse off than others through no fault or choice of her own, period - that is, regardless of where she lives, or where others live. If a person in Sierra Leone is worse off than a person in Sweden, through no fault or choice of her own, this constitutes an injustice, and ought ideally to be rectified. Thus, this view rejects the idea that justice requires, say, shared

\footnotetext{
${ }^{19}$ This is not to say that our discussion is completely equalisandum-independent. For instance, it could be the case that (global luck-) capabilitarianism would have other implications than those we attribute to GLE.

${ }^{20}$ See Lippert-Rasmussen (1999); Vallentyne (2002).
} 
political institutions, common nationality or reciprocal cooperation. Instead, GLE counts as unjust all unchosen inequalities between all individuals wherever they happen to be. ${ }^{21}$

What implications can we expect GLE to have for the question of border control? As indicated above, we believe that the implications of GLE on immigration in general, and the justifiability of closed borders in particular, will rest on a host of empirical questions, the truth of which is hard to ascertain in a theoretical paper. (We return to this issue below.) Even so, some general theoretical discussion is arguably warranted as a first stab at assessing the implications of GLE on border control. It has often been pointed out that where we are born has an immense impact on our welfare and life prospects. However, we do not, of course, have any influence over where we are born. It seems then that the differences in welfare that arise because of differences in birth-place are of a kind that GLE would find unjust. Initially, then, closed borders seem most likely to freeze (many) unjust inequalities. If so, open borders, or more open borders, at least, would seem like one possible solution to this injustice.

According to Carens $(1987,252)$ "Citizenship in Western liberal democracies is the modern equivalent of feudal privilege - an inherited status that greatly enhances one's life chances." 22 That sounds right, and it would be implausible to claim, initially at least, that GLE would, in general, be better served by closed borders, than by open borders, in our current world. ${ }^{23}$ We shall therefore start from the tentative hypothesis that GLE is an ideal for global

\footnotetext{
${ }^{21}$ Note that GLE would presumably be concerned with such inequalities between members belonging to different generations too - thus we should (relevantly) equalize people's welfare not only wherever people happen to be, but also whenever people happen to exist. The same is the case for LE. We leave the intergenerational aspect aside in this paper, however.

${ }^{22}$ See also Fabre, 2005, 142.

${ }^{23}$ And indeed in most nearby conceivable worlds.
} 
distributive justice that will (typically) have rather liberal implications for the question of border control.

Some authors, however, seem to suggest a stronger connection than this between open borders and GLE (and closely related views, such as global equality of opportunity). The idea seems to be that there is a principled link between them, such that a commitment to the latter will always imply a (pro tanto) commitment to the former. In a recent review of political theories of migration, Sarah Song describes a main category of arguments in favor of open borders as committed to the view that "global equality of opportunity requires open borders" (2018, 389). At times, Joseph Carens also comes close to assert such a principled connection between equal opportunity and open borders. As he puts it, "freedom of movement is essential for equality of opportunity. You have to be able to move to where the opportunities are in order to take advantage of them. [...] [T]he conventional pattern of border controls greatly restricts opportunities for potential immigrants" $(2013,557)$.

As will become clear, our analysis denies any such principled connection. As we see it, GLE implies a commitment to open borders only as a matter of empirical contingency. Yet, in our current world, GLE will typically support (much) more open borders. ${ }^{24}$ In the following, we shall explore whether this view can withstand more sustained scrutiny. First, however, it will be helpful to outline the approach we shall use when addressing what GLE implies for border control.

\section{A Note on Methodology}

When we ask 'what, if anything, GLE implies for justified border control policies', we could aim to discover at least two things. On the one hand, we could seek to determine what an ideal world would look like according to GLE. That is, in a world where people would generally

\footnotetext{
${ }^{24}$ We expect (but shall not demonstrate) that the same holds for closely related views, such as global equality of opportunity.
} 
comply with GLE's demands, which border policies, if any, would exist? On the other hand, we could ask what we should do, here and now (border policy wise), to best move towards a world governed by GLE. That is, in current circumstances - where (very) many people do not live up to the demands of justice - are there any particular border control policies we should implement when trying to achieve a more just world? Following Rawls's terminology, these two versions of the question fall within 'ideal' and 'non-ideal' theory, respectively. As Rawls puts it, ideal theory identifies "the principles of justice that would regulate a well-ordered society [in which] [e]veryone is presumed to act justly and to do his part in upholding just institutions" (Rawls 1999b, 8). Nonideal theory, on the other hand, "asks how this [ideal] might be achieved, or worked toward, usually in gradual steps" (Rawls 1999a, 89).

Ideal theory is arguably indispensable. Unless we have first identified the ideal target, non-ideal theory would lack the necessary direction (Rawls 1999a, 89-90; Simmons 2010; Stemplowska and Swift 2012). ${ }^{25}$ Although our present analysis takes GLE for granted, we recognize that there is important work to be done in defending it as an ideal of global distributive justice. Many believe, for example, that collective self-determination has considerable value (Miller 2007 and 2016; Altman and Wellman 2009). They are skeptical about whether GLE (or roughly similar egalitarian proposals) can allow groups a meaningful degree of selfdetermination, and tend to reject GLE for that, and other, reasons. To counter such criticism, a defense of GLE could try to demonstrate that GLE is compatible with meaningful selfdetermination, or that we should accept whatever (circumscribed) scope GLE implies as

\footnotetext{
${ }^{25}$ This view, it should be noted, is not without its critics. Sen (2009), for example, argues that we may recommend specific actions in nonideal theory - with an aim to decrease the amount of injustice in the world without prior knowledge of what perfect justice requires. For a convincing rejection of this view, see Simmons (2010).
} 
demanded by justice. ${ }^{26}$ These issues of justification, which fall within the domain of ideal theory, are undoubtedly important. For present purposes, however, we set them aside. ${ }^{27}$ Our question instead falls within non-ideal theory: taking GLE for granted, we ask what it implies about which border control policies we should follow, here and now, in our pursuit of ideal justice.

Which methodological implications follow from this aim? When we engage in nonideal theory, we "[look] for policies and courses of action that are morally permissible and politically possible as well as likely to be effective" (Rawls 1999a, 89). In light of these variables (permissibility, feasibility, and effectiveness), it seems safe to say that making policy recommendations in nonideal theory will often be a daunting task. When determining whether we should pursue policy $\mathrm{P}$, we must not only draw upon an enormous amount of empirical evidence from the social and other sciences to assess the political feasibility and effectiveness of policy $\mathrm{P}$ (and its alternatives). If our recommendation is to be the 'best' policy overall, we must also take into account all the relevant moral considerations (other than justice) which may influence a nonideal proposal's moral permissibility.

We must therefore limit our inquiry in various ways, in order to make it manageable. We make two moves to that effect. First, we focus on GLE as our only ideal target. This means that we set other ideals aside, and assume away any influence they may have on what we should do here and now. For our purposes, GLE is the sole issuer of demands. ${ }^{28}$ This is a simplification, of course. Yet, it is arguably justified for the sake of analytical economy and clarity. Our aim

\footnotetext{
${ }^{26}$ See Fabre (2005, 152-162) for a discussion.

${ }^{27}$ For a helpful discussion of the compatibility between collective self-determination and various versions of global egalitarianism, see Armstrong (2010).

${ }^{28}$ We assume, as noted, that GLE encompasses a concern with utility. On such a view, equality is important, but more welfare is better than less.
} 
is to determine what we have reason to do here and now (concerning border policies) from the point of view of justice. The reasons we shall identify are thus pro tanto in nature. They have genuine weight, yet fall short of telling us what we should do overall. Our nonideal analysis will thus identify only one part of the relevant picture. Yet, such an analysis of pro tanto reasons is arguably a helpful step to determine what we have reason to do overall, in light of all relevant ideals. (The pro tanto reasons given by other ideals might be identified through similarly compartmentalized analyses.) Thus, we aim to contribute to the development of nonideal theory, not to state it in full.

Second, because GLE is a very distant ideal (as it seems reasonable to assume), we cannot aim to recommend a path all the way towards its realization. As noted, that would require access to enormous amounts of empirical data and scientific knowledge (much of which is presumably yet to be uncovered and not forthcoming any time soon). Such recommendation is therefore not reasonably expected of any single article. If we want to make headway in nonideal theory, it is fair to say that our goal must typically be much more modest. We shall therefore not identify a path all the way from the status quo to a just world. Instead, our analysis shall throw light on the empirical assumptions that must hold if different kinds of border policies are to bring us closer towards the global luck egalitarian ideal.

\section{What Implications does GLE have for Border Control?}

Our tentative hypothesis at the outset was that global, individualist GLE is likely to condemn a policy of closed borders, at least in many situations. Is this hypothesis correct? Let us start by reiterating our belief that the connection between GLE and open borders is not a principled one. In our view, it is quite easy to imagine situations in which GLE permits or even requires closed borders. Thus, one could argue that GLE has no particular implications for the question of 
border control. Whether the principle permits or requires open or closed borders simply depends on whether open or closed borders will contribute to realize GLE.

Consider some closed border cases in which GLE would not demand opening borders.

1. No one is worse off than others through no fault or choice of their own. Opening borders will make no difference with regards to injustice. Closed borders are permitted by GLE.

2. No one is worse off than others through no fault or choice of their own. Opening borders will increase injustice. Closed borders are required by GLE.

3. At least some (perhaps many) are worse off than others through no fault or choice of their own. Opening borders will make no difference with regards to injustice. Closed borders are permitted by GLE.

4. At least some (perhaps many) are worse off than others through no fault or choice of their own. Opening borders will increase injustice. Closed borders are required by GLE.

It is clear, however, that such scenarios are highly unlikely. The two first, in particular, can be dismissed out of hand, since we know for sure that the present world is not just as judged by GLE. In our world, now and in the foreseeable future, people will not be justly equally well off, and their welfare will be heavily influenced by where they live (among other things). What about scenarios 3 and 4 ? Is it possible that opening borders will have no, or negative, effects on global luck egalitarian justice?

Intuitively, we find it hard to imagine that, in our current world, a policy of opening borders (more, if not completely), would not bring us closer to what GLE regards as a just state of affairs. Whenever some person who is unjustly worse off than others could become better off (without making some other person [more] unjustly worse off than others), by moving to, and settling in, another country, GLE would presumably mandate opening the borders for this person. Most likely, there are many such persons. Consider just a few well-known, but harsh 
facts. According to WHO, healthy life expectancy (HALE) ranges from 45,9 years in Angola (and similar numbers in several African countries) to 74.9 years in Japan (and just slightly less in many Western European Countries). ${ }^{29}$ The maternal mortality ratio (pr. 100000 live births) ranges from only three in several European countries to a staggering 1360 in Sierra Leone. ${ }^{30}$ Such numbers are only indicative of course, but the point is perfectly clear. People's place of birth has a very strong influence over their life prospects as well as their quality of life. Given the unjust inequality in our present world, it seems overly plausible that it is true, for a great many individuals, that moving from one country to settle in another would improve their welfare, and reduce the relevant form of unjust inequality between those who move and many of those who are better off. ${ }^{31}$

Consider for illustration, the opposite proposition. Imagine that you live in an affluent western country. Do you think that moving yourself from your current place of residence, to, say, Sierra Leone (with no special privileges) would affect your life prospects for the worse? We are convinced that such a move (and similar moves), would affect the life prospects of many individuals from affluent western states for the worse, and that the burden of proof rests squarely with those who want to deny this.

One might still wonder, though, for any such move, whether this would actually reduce unjust inequality or not. For one thing, GLE requires that no one should be worse off than others through no fault or choice of her own. We cannot know, on the individual level, who is and who is not responsible for their level of welfare. In reply, it is worth repeating that one's place

\footnotetext{
${ }^{29} \mathrm{http}: / /$ apps.who.int/gho/data/view.main.HALEXv. The numbers are form 2015.

${ }^{30} \mathrm{http}: / / a p p s$. who.int/gho/data/node.main.MATMORT?lang=en. The numbers are form 2015.

${ }^{31}$ According to the World Bank, "in 2013, 10.7 percent of the world's population lived on less than US\$1.90 a

day." While this is an improvement, the extent of world poverty and inequality is still

massive. http://www.worldbank.org/en/topic/poverty/overview. See also Holtug (2017: 129).
} 
of birth is paradigmatically beyond one's control. Thus, reducing unjust inequalities stemming from this fact in particular, would (all else equal) be a good thing from the point of view of GLE. Presumably, people who are badly off, partly in virtue of factors that are clearly not their fault, would then be made better off relative to people who are well off, partly in virtue of factors that are clearly not their fault. To the extent that this is so, it is very hard to see why one would expect the overall result to be negative from GLE's point of view. ${ }^{32}$

All in all then, in our view, there are many considerations that suggest that more open borders would, all else equal, reduce the global amount of unjust inequalities.

\section{Some Reasons to Doubt that Open Borders will Contribute to GLE}

Despite the initial reasons to think that GLE would recommend more open borders, others might point in a different direction. In this section, we consider three such important concerns. The first focuses on implications for inhabitants in sender countries, whereas the second and third consider effects on receiver countries.

\subsection{Brain Drain}

According to David Miller, pursuing an open borders policy is not a fruitful way of achieving global egalitarian justice $(2016,48) .{ }^{33}$ The reason is that it is primarily the elites in poor countries who will have the resources to emigrate, ${ }^{34}$ and this will in turn threaten not only to unjustly widen the gap between the (former) elite and non-elite of poor countries, but also to reduce the welfare of the non-elite in absolute terms, due to brain drain (Miller 2016, 48).

\footnotetext{
${ }^{32}$ This is not to deny that there could be individual exceptions.

${ }^{33}$ Miller argues primarily against an ideal of global equality of opportunity. His arguments concerning this point seem equally pertinent for GLE, however.

34 This argument is also made by Holtug $(2010,448)$.
} 
There are two claims here, then. Open borders will (i) increase unjust inequality between elites and non-elites in sender countries, and (ii) make the non-elite in sender countries worse off in absolute terms. The first claim, even if correct, is not necessarily relevant. If the elites emigrate and thereby decrease the gap between themselves and people in recipient countries, while simultaneously increasing the gap between themselves and the non-elites in their country of origin to a similar degree, the extent of unjust inequality would arguably be the same, whereas an increase in utility would have been secured. ${ }^{35}$ For egalitarians who value increases in welfare, this would not necessarily be problematic. ${ }^{36}$ For a simple illustration, consider the two following, scenarios (where R denotes 'receiver country', S denotes 'sender country', and the numbers refer to the welfare levels that individuals belonging to the respective groups have obtained solely as a matter of brute luck): $:^{37}$

\section{A. Closed borders:}

Citizens of $\mathrm{R} \quad$ Elites in $\mathrm{S}$ (prior to emigration) Non-elites in $\mathrm{S}$

B. Open borders:
Citizens of $\mathrm{R}$
Elites in S (after emigration)
Non-elites in S

\footnotetext{
${ }^{35}$ Of course, inequality, and its badness, can be measured in different ways. For an extensive discussion, see Temkin (1993).

${ }^{36}$ See Holtug (2017: 131) for a related point. Note that many egalitarians would also be willing to make a tradeoff between equality and utility (within certain limits).

${ }^{37}$ As we explained in Section 2, a person's place of birth typically has immense effects on his or her welfare and life prospects. In these stylized scenarios, we therefore assume, for the sake of simplicity, that there are no other sources of brute luck than one's place of birth. Opening borders thus has at least prima facie plausibility as an antidote to the relevantly unjust differences in the indicated welfare levels people enjoy.
} 
In $B$, for the elites in $\mathrm{S}$ (after emigration) there is a decrease in unjust inequality of five points relative to the citizens of $\mathrm{R}$, and an increase in unjust inequality of five points relative to the non-elites in $\mathrm{S}$. To insist that scenario $B$ is worse than $A$ requires some specific justification for which inequalities are worse than others. It would also seem to require acceptance of a version of leveling down (Parfit 1997). All in all, the first problem identified by Miller seems irrelevant.

The second problem, however, is more challenging. It could be the case that, if elite members leave, this will make members of the non-elite in sender countries worse off in an absolute sense, for instance because the elites have expertise and competences that are badly needed in their home country (brain drain). To illustrate, consider the following pair of scenarios:

A. Closed borders:

Citizens of $\mathrm{R} \quad$ Elites in $\mathrm{S}$ (prior to emigration) Non-elites in $\mathrm{S}$

C. Open borders:

Citizens of $\mathrm{R} \quad$ Elites in $\mathrm{S}$ (after emigration) Non-elites in $\mathrm{S}$ 20 10 1

In this situation, GLE would not necessarily mandate open borders for the relevant elites, since unjust inequality would then increase. (For the elites in S [after emigration], although there is a decrease in unjust inequality of five points relative to the citizens of $\mathrm{R}$, there is an increase of six points relative to the non-elites in S. Thus, the level of unjust inequality between the citizens 
of $\mathrm{R}$ and the non-elites in $\mathrm{S}$ increases with one point.) Moreover, because the non-elites in this stipulated example also become absolutely worse off in $C$, many versions of GLE, we expect, would find (further) reason to oppose opening borders. ${ }^{38}$

It is important to consider the issue more closely, however. For GLE to demand closed borders, it has to be true (not merely stipulated) that the worst-off - the Non-elites in S - actually become worse off. The empirical evidence here is mixed. Measures such as remittances from emigrants might actually make the worst off better off, despite brain drain. ${ }^{39}$ Other times brain drain may cause serious harm (Oberman 2013, 429). Evidence further suggests that the effects of brain drain may vary with characteristics of sender countries, and that "... the conditions under which a country is gaining or losing [from brain drain] are not a matter of fate; to a large extent, they depend on the public policies adopted in the receiving and sending countries" (Docquier and Rapoport 2012, 725). ${ }^{40}$

Nonetheless, even if it is sometimes true that the worst off are made even worse off if the elite is allowed to emigrate, borders would remain open to all those whose emigration would not in fact make the worst off even worse off. So, even if brain drain is sometimes detrimental to the worst off (and produce an increase in unjust inequalities), this cannot mandate a general policy of closed borders. It can only justify closing the borders to those whose emigration would make the worst off worse off. ${ }^{41}$ For all others, including, notably, the non-elites, borders would remain open. Even though the non-elites may have a harder time leaving, it is not impossible

\footnotetext{
${ }^{38}$ But note that different versions of GLE might weight equality and utility in different ways, and some versions might favor scenario $C$ over scenario $A$.

${ }^{39}$ See for instance Holtug $(2010,446)$.

${ }^{40}$ See also Marhciori et al. (2013, 1597).

${ }^{41}$ There are other issues here, such as personal freedom of movement (Oberman 2013). Although we do not discuss them, they are of course parts of the broader picture.
} 
for them to do so, especially if borders are not closed to them. ${ }^{42}$ Thus, GLE would imply closing borders to those whose emigration would make matters worse for the worst off, but borders would remain open to all those for whom this was not true, including presumably most individuals from sender countries that are not part of the elite.

\subsection{Increasing Injustice in Receiving Countries}

Let us now shift our main focus to the receiver countries, and consider whether a proponent of GLE has reason to worry about potentially counterproductive effects of opening borders. We shall consider two such potential effects. The first concerns the risk of increasing unjust inequalities in receiver countries (which might offset gains elsewhere). The other concerns very large welfare losses following from the economic costs of increased immigration. Such costs might be prohibitive, regardless of how open borders will influence the level of unjust inequality in the world.

In scenarios $A, B$, and $C$, we assumed that the citizens of receiving countries form a homogenous group welfare-wise. The welfare level enjoyed by any citizen of these countries remained the same regardless of border policy. This is a simplification, of course. Let us therefore now consider whether a policy of opening or closing state R's borders might create unjust divisions among R's original citizens. If borders are opened up, one might suggest, this can be expected to make some citizens of R, such as capital owners, (much) better off (e.g. by giving them access to a larger work force, with more people willing to work for less), whereas others, typically non-skilled workers, become worse off (e.g. due to downward pressure on

\footnotetext{
${ }^{42}$ Also, furher measures could be implemented in order to assist the non-elites.
} 
wages). ${ }^{43}$ Now, imagine that such mechanisms in the wake of an open borders policy serve to divide R's initial citizenry into elites and non-elites:

A. Closed borders:

\section{Citizens of $\mathrm{R}$}

20
Elites in S (prior to emigration)

5
Non-elites in S

2

\section{Open borders:}

Elites in $\mathrm{R} \quad$ Non-elites in $\mathrm{R} \quad$ Elites in $\mathrm{S}$ (after emigration) Non-elites in $\mathrm{S}$ 30 10 10 2

In $D$, the amount of unjust inequalities has increased between the elites in $\mathrm{R}$ and everyone else. It has increased with 20 points (from zero) compared to the non-elites in R, with five points (from 15) compared to the emigrated elites in S, and with ten points (from 18) compared to the non-elites in S. On the other hand, $D$ eradicates the previous unjust inequality between the emigrated elites in $\mathrm{S}$ and those people who are now members of its non-elite. (Between those groups, the differential goes from 15 points to zero.) Confronted with $A$ and $D$, it might thus be unclear whether GLE would give pro tanto support for opening borders or keeping them closed, or whether a (more) neutral stance is appropriate. The answer would depend on the changes in unjust inequalities that were brought about, the welfare levels of the groups, and the evaluation of different forms of inequality. In general, however, it seems that increased unjust inequality between some groups might be a risk associated with increased immigration. This consequence is not certain, though, and even if it occurs, its badness must be evaluated in an overall

\footnotetext{
${ }^{43}$ For an analysis along such lines, see Macedo (2011) and Cafaro (2015). Again, we assume that the inequalities are unchosen.
} 
assessment. (Here too, however, giving the non-elites in S easier access might mitigate some of the [potential] negative effects).

\subsection{Welfare Costs of Open Borders}

One might also worry that opening borders overnight risks imposing massive economic costs on each receiving country, and lead to significant welfare losses for its citizens. To illustrate, consider the following pair of scenarios:

A. Closed borders:

Citizens of $\mathrm{R} \quad$ Elites in $\mathrm{S}$ (prior to emigration) Non-elites in $\mathrm{S}$

E. Open borders:

Citizens of $\mathrm{R} \quad$ Elites in $\mathrm{S}$ (after emigration) Non-elites in $\mathrm{S}$

Here we imagine that state R's institutions have become financially incapable of sustaining high-quality public services, such that its citizens experience a significant drop welfare-wise, whereas the newly arrived migrants from $\mathrm{S}$ gain nothing. Note first that changing from $A$ to $E$ reduces the level of unjust inequality in the world. In $E$, the citizens of $\mathrm{R}$ and the newly arrived members of the elites from S enjoy the same level of welfare. Moreover, the gap between the citizens of $\mathrm{R}$ and the non-elites in $\mathrm{S}$ has dropped from 18 to three. However, this decrease happens through the mere elimination of significant amounts of welfare for the citizens of R, without any welfare-gains for others. As was the case with our comparison between $D$ and $A$, a proponent of GLE might have a hard time deciding whether we have reason to pursue $E$ over 
$A$. On the one hand, $E$ now contains less relevant inequality. On the other hand, $E$ contains a very significant welfare-loss in absolute terms for some, without any such gains for others. Our aim is not so much to determine what the GLE-proponents ought to recommend here, as to bring light to the options and difficulties involved.

At any rate, any prima facie liberal implications that GLE has for border control, must be scrutinized in light of the potential welfare effects of economic cost imposition. Again, to determine such effects would require complex empirical assessments, many of which would arguably require scientific studies and significant amounts of empirical data not yet at hand. Having said that, what does the empirical evidence produced thus far say? The message is arguably mixed. According to Borjas $(2015,962)$, much economic literature has suggested that “...the global gains from the removal of immigration restriction would be huge, amounting to trillions of dollars annually." He goes on to nuance this assumption, however, arguing that many previous studies have underplayed the costs of mass migration: “...the gains from unrestricted immigration depend largely on how the infrastructure in the receiving economies adjusts to the influx of perhaps billions of persons". $(2015,970)$

It seems fair to say that the economic and social effects of completely open borders are largely unknown. There are potential gains and costs that are very hard to predict. ${ }^{44}$ Even so, this is perfectly compatible with gradually opening borders for many, and monitoring the effects closely. It does not seem that empirical studies so far rule out the possibility of (far more) open borders than we see today. Again, however, it is important to emphasize that GLE gives us pro tanto reason to open borders only to the extent that this would in fact promote justice.

\footnotetext{
${ }^{44}$ See also the discussion in Holtug 2010.
} 


\section{Concluding Remarks}

We can safely say that many of the worse off in poor countries are worse off in part because of where they are born. Similarly, many of the well off in rich countries are well off in part because of where they are born. Where a person is born, and where she happens to live her life, is typically beyond her control. Assuming that many other morally relevant factors are equal, then, the poor are worse off than the rich for reasons that are clearly beyond their control. According to GLE this counts as an injustice. Generally, more open borders might be one way (among several) of addressing this injustice, because letting the global poor move to and settle in rich countries, might make these poor people less unjustly worse off than others.

We have considered some objections to this general idea. More open borders might lead to more injustice, either within the sender or receiving country, or across countries. Further, more open borders might lead to substantial welfare loss, insofar as unchecked immigration threatens the economic viability of various welfare programs in receiving states. There are two lessons to draw from this. First, GLE would not mandate opening all borders overnight. The consequences of doing so would be too uncertain in terms of approaching ideal justice. Second, however, in all cases in which granting an immigrant access will reduce unjust inequalities, such access should be granted, unless associated welfare losses are big enough to offset the justice gains. Moreover, granting access to a substantial number of the worst off from poor countries, is very unlikely to cause difficulties related to brain drain. Further, until decreasing labor prices (or other factors) actually starts to produce unjust inequalities (large enough to offset the reduction of such inequalities associated with immigration), GLE gives pro tanto reason to keep borders (partially) open. The same goes for the economic costs of open borders. Such assumed costs cannot be used as an argument for closing borders, in the light of GLE (all the more so because of the empirical uncertainties involved). Borders should remain open until 
the costs materialize, and until they are large enough to offset any justice gains associated with immigration.

Thus, on the assumption that unjust inequalities are not counteracted through other means, GLE would demand more open borders, and that borders remain open until and if potential negative effects offset the positive effects. Further, borders may in many cases be open to some individuals and not others. Granting access to the worst off from poor countries will in most cases lead to more justice gains than granting access to less worse off people from these countries. $^{45}$

Lastly, we would like to repeat that we do not claim that open borders is in any way inherent to the ideal of GLE. Surely, there may be other roads to justice. It is possible, for instance, to achieve justice - to eliminate inequalities arising from differential brute luck through schemes of massive resource redistribution (across otherwise closed borders). Many such measures can be taken, both domestically and internationally. Domestically, investment in industry and increased welfare programs might help those who are unjustly worse off than others. Internationally, foreign aid and assistance to the worst off in poor countries may also help combat unjust inequalities, not to mention large-scale global redistribution, and fair trade agreements. Thus, there is no reason to think that open borders is the only solution, nor that it is sufficient on its own (see also Carens 1987, 261). However, in the unjust world in which we live, a policy of open borders, within the constraints discussed above, is likely to make our world more just than it currently is. Unless people of affluent states start to massively engage in alternative measures, GLE gives pro tanto reason to pursue a policy of (much) more open borders whenever the relevant empirical conditions obtain.

\footnotetext{
${ }^{45}$ However, emigration of the poor - when they are young and talented (yet uneducated) - might have other negative effects on the prospects for creating local development.
} 
Centre for Philosophy and Public Policy Department of Learning and Philosophy Kroghstraede 3 DK-9220 Aalborg $\varnothing$

Denmark

Email:kian@learning.aau.dk

University of Oslo Department of Political Science Moltke Moes vei 31 0851 Oslo Norway Email:roberthu@stv.uio.no 


\section{References}

Altman, Andrew and Christopher Heath Wellman. 2009. A liberal theory of international justice. Oxford University Press.

Anderson, Elisabeth. 1999. What is the Point of Equality? Ethics 109: 287-337.

Armstrong, Chris. 2010. National Self-Determination, Global Equality and Moral Arbitrariness. Journal of Political Philosophy 18: 313-334.

Arneson, Richard J. 2016. Extreme Cosmopolitanism Defended. Critical Review of International Social and Political Philosophy 19: 555-573.

Arneson, Richard. 2011. Luck Egalitarianism - A Primer. In Responsibility and Distributive Justice, eds. Carl Knight and Zofia Stemplowska. Oxford: Oxford University Press. Arneson, Richard. 1989. Equality and Equal Opportunity for Welfare. Philosophical Studies 56: 77-93.

Beitz, Charles. 1979. Political theory and International Relations. Princeton, NJ: Princeton University Press.

Blake, Michael. 2001. Distributive Justice, State Coercion, and Autonomy. Philosophy and Public Affairs 30: 257-296.

Borjas, George J. 2015. Immigration and Globalization: A Review Essay. Journal of Economic Literature 53: 961-974.

Brock, Gillian. 2015 (Spring Edition). "Global Justice", The Stanford Encyclopedia of Philosophy, Edward N. Zalta (ed.), $\mathrm{URL}=<$ http://plato.stanford.edu/archives/spr2015/entries/justice-global/>.

Butt, Daniel. 2009. Rectifying international injustice - principles of compensation and restitution between nations. Oxford: Oxford University Press.

Cafaro, Philip (2015): How Many Is Too Many? Chicago: The University of Chicago Press. Caney, Simon. 2005. Justice Beyond Borders - A Global Political Theory. Oxford: Oxford 
University Press.

Carens, Joseph. 2013. The Ethics of Immigration. New York: Oxford University Press.

Carens, Joseph. 1987. Aliens and Citizens: The Case for Open Borders. Review of Politics 49:251-273.

Cohen, G. A. 2011. On the Currency of Egalitarian Justice, and other Essays in Political Philosophy, edited by Michael Otsuka. Princeton and Oxford: Oxford University Press.

Cohen, G. A. 2008. Resuing Justice and Equality. Cambridge MA.: Harvard University Press.

Docquier, Frédéric, and Hillel Rapoport. 2012. Globalizaiton, Brain Drain, and Development. Journal of Economic Literature 50: 681-730.

Dworkin, Ronald. 2000. Sovereign Virtue. Cambridge MA.: Harvard University Press.

Eyal, Nir. 2006. Egalitarian Justice and Innocent Choice. Journal of Ethics and Social Philosophy 2: 1-18.

Fabre, Cécile. 2005. Global Distributive Justice: An Egalitarian Perspective. Canadian Journal of Philosophy 35: sup. 1, 139-164.

Holtug, Nils. Forthcoming. Luck Egalitarianism and the Rights of Immigrants. Ratio Juris.

Holtug, Nils. 2010. Immigration and the Politics of Social Cohesion. Ethnicities 10: 435-451.

Knight, Carl. 2009. Luck Egalitarianism: Equality, Responsibility, and Justice. Edinburgh: Edinburgh University Press.

Lippert-Rasmussen, Kasper. 2016. Luck Egalitarianism. London: Bloomsbury Academic.

Lippert-Rasmussen, Kasper. 1999. Debate: Arneson on Equality of Opportunity for Welfare.

The Journal of Political Philosophy 7: 478-487.

Lister, Matthew. 2013. Who are Refugees? Law and Philosophy 32: 645-671.

Macedo, Stephen (2011): When and Why Should Liberal Democracies Restrict Immigration?

In Rogers, M. Smith (ed.): Citizenship, Borders, and Human Needs. Philadelphia: University of Pennsylvania Press. 
Marchiori, Luca, I-Ling Shen, and Frédéric Docquier. 2013. Brain Drain in Globalization: A General Equilibrium Analysis from the Sending Countries' Perspective. Economic Inquiry 51: $1582-1602$.

Miller, David. 2007. National Responsibility and Global Justice. Oxford: Oxford University Press.

Miller, David. 2016. Strangers in Our Midst - The Political Philosophy of Immigration. Cambridge MA and London: Harvard University Press.

Nagel, T., 2005. The Problem of Global Justice. Philosophy and Public Affairs 33 (2), $113-147$.

Oberman, Kiean. 2013. Can Brain Drain Justify Immigration Restriction? Ethics 123: 427-455. Parfit, Derek. "Equality and Priority," Ratio 10 (1997): 202-221

Pogge, Thomas. 1994. Realizing Rawls. Ithaca, NY: Cornell University Press.

Pogge, T., 2002. World Poverty and Human Rights. Cambridge: Polity Press.

Rawls, J., 1999a. The Law of Peoples. Cambridge MA: Harvard University Press.

Rawls, John. 1999b. A Theory of Justice. Oxford: Oxford University Press.

Scheffler, Samuel. 2003. What is Egalitarianism? Philosophy and Public Affairs 31: 5-39.

Shacknove, Andrew. 1985. Who is a Refugee? Ethics 95: 274-284.

Sen, Amartya. 2009. The Idea of Justice. Cambridge, MA: Harvard University Press.

Simmons, A. John. 2010. Ideal and Nonideal Theory. Philosophy and Public Affairs 38(1): 536.

Singer, Peter. 1971. Famine, Affluence, and Morality. Philosophy \& Public Affairs 1: 229243.

Song, Sarah. 2018. Political Theories of Migration. Annual Review of Political Science 21: 385402.

Steiner, Hillel. 1981. Liberty and Equality. Political Studies 29: 555-569. 
Steiner, Hillel. 1994. An Essay on Rights. Oxford: Blackwell.

Tan, Kok-Chor. 2012. Justice, Institutions, \& Luck. Oxford: Oxford University Press.

Temkin, Larry. 1993. Inequality. Oxford: Oxford University Press.

Vallentyne, Peter. 2002. Equality, Brute Luck and Initial Opportunities. Ethics 112: 529-557.

Wellman, C. H. and P. Cole (2011) Debating the Ethics of Immigration - Is there a Right to Exclude? Oxford: Oxford University Press.

Williams, Andrew. 2006) Liberty, Equality, and Property. In The Oxford Handbook of Political Theory, eds. John. S. Dryzek, Bonnie Honig, and Anne Phillips. Oxford and New York: Oxford University Press. 